\title{
Proteinuria and the Clinical Course of Dobrava-Belgrade Hantavirus Infection
}

\author{
Markus Meier ${ }^{a}$ b Jan Kramer ${ }^{a, c} \quad$ Wolfram J. Jabs ${ }^{a, d} \quad$ Claudia Nolte ${ }^{a, e}$ \\ Jörg Hofmann ${ }^{f}$ Detlev H. Krüger ${ }^{f}$ Hendrik Lehnert ${ }^{a}$ Martin Nitschke ${ }^{a}$ \\ a Division of Nephrology, Medical Clinic I, University of Lübeck, Lübeck, Germany; \\ ${ }^{b}$ Nephrology Center Reinbek and Geesthacht, Reinbek, Germany; ${ }^{C}$ LADR, Central \\ Laboratory Dr. Kramer and Colleagues, Geesthacht, Germany; ${ }^{d}$ Department of Nephrology, \\ Vivantes Klinikum im Friedrichshain, Berlin, Germany; ${ }^{\mathrm{e}}$ General Outpatient Clinic, \\ Horneburg, Germany; ${ }^{{ }}$Institute of Medical Virology, Helmut-Ruska-Haus, Charité Medical \\ School, Berlin, Germany
}

\section{Keywords}

Dobrava-Belgrade virus · Hantavirus · Acute kidney injury · Interstitial nephritis ·

Hemorrhagic fever with renal syndrome

\begin{abstract}
Purpose: Human infection with Dobrava-Belgrade virus (DOBV) in Northern Germany causes a mild form of hantavirus disease predominantly characterized by acute kidney injury due to interstitial nephritis. We evaluated the largest number of DOBV-infected patients so far regarding clinical course, proteinuria, and prognostic markers. Patients and Methods: Patients with DOBV-associated hantavirus disease admitted to the Renal Division of the University of Lübeck (Germany) between 1997 and 2012 were included in this study. Symptoms, clinical course, laboratory parameters, and urinary protein analysis were investigated at admission (baseline, $\left.t_{0}\right), 3-5$ days $\left(t_{3-5}\right), 10-17$ days $\left(t_{10-17}\right)$, and after 1 year of follow-up ( $\left.t_{365}\right)$. Results: Of the 34 patients (male/female ratio: 23/11; age: $41 \pm 14$ years) included in the study, 4 underwent hemodialysis (HD). Glomerular filtration rate was $17 \pm 14 \mathrm{~mL} / \mathrm{min}$ at $\mathrm{t}_{0}$ and increased to $27 \pm 26 \mathrm{~mL} / \mathrm{min}\left(\mathrm{t}_{3-5}\right), 57 \pm 20 \mathrm{~mL} / \mathrm{min}\left(\mathrm{t}_{10-17}\right)$, and $84 \pm 16 \mathrm{~mL} / \mathrm{min}\left(\mathrm{t}_{365}\right)$. Albuminuria and tubular proteinuria $\left(\alpha_{1}-\right.$ and $\beta_{2}$-microglobulin) decreased during follow-up; the urinary $\alpha_{1^{-}}$ microglobulin concentration in patients who required $\mathrm{HD}$ was significantly higher than that in patients not requiring $\mathrm{HD}$ ( $\mathrm{t}_{0}: 186 \pm 51$ vs. $45 \pm 26 \mathrm{mg} / \mathrm{g}$ creatinine; $\mathrm{t}_{3-5}: 87 \pm 14 \mathrm{vs} .32 \pm 16$ $\mathrm{mg} / \mathrm{g}$ creatinine; $\mathrm{t}_{10-17}: 63 \pm 18$ vs. $28 \pm 12 \mathrm{mg} / \mathrm{g}$ creatinine; $\left.p<0.001\right)$. Conclusions: DOBV infection of inpatients in Northern Germany is associated with severe kidney injury that recovers within a few weeks and normalizes within 1 year. Tubular proteinuria is associated with the severity of kidney injury and the necessity of renal replacement therapy in these DOBV-infected patients.


Meier et al.: Dobrava-Belgrade Hantavirus Infection

\section{Introduction}

Worldwide, approximately 60,000-150,000 people are hospitalized every year with hantavirus infections. In Germany, up to 3,000 cases of hantavirus disease are registered annually [1]. Hantaviruses (Bunyaviridae family) are single-stranded, negative-sense RNA viruses that reside asymptomatically in small animals as natural hosts and are transmitted to humans via aerosolized urine, saliva, or feces of the infected animals. In humans they cause two potentially fatal febrile diseases, namely hemorrhagic fever with renal syndrome (HFRS) and hantavirus cardiopulmonary syndrome [2, 3]. Instances of transmission through humanto-human contact are only anecdotally reported from South America.

Different hantaviruses can exhibit different pathogenicity in humans, with case fatality rates of up to 50\% [3]. In Europe, Puumala virus (PUUV) and Dobrava-Belgrade virus (DOBV), naturally hosted by bank voles and various Apodemus mice species, respectively, are the most important pathogens $[3,4]$. The DOBV species encompasses different virus types with quite different virulence in humans; these are the type Dobrava and the type Sochi causing moderate to severe HFRS on the Balkans and in Southern European Russia on the one hand and the Kurkino type on the other [5]. So far, groups of HFRS patients infected by DOBV-Kurkino were reported from European Russia [6] and Northeastern Germany [7]. It seems that the clinical course after DOBV-Kurkino infection is rather mild with a case fatality rate of about $0.5 \%$, resembling those of PUUV infections [6-8]; however, also severe cases exhibiting not only renal but also pulmonary failure have been described [9].

Whereas extensive clinical characterization of HFRS caused by PUUV (also called nephropathia epidemica [NE]) and DOBV-Dobrava have been published by some authors mainly from Finland, Sweden, Germany, and Southeastern Europe, there is an urgent need to estimate clinical criteria, including parameters of disease severity and prognosis, for patients infected by DOBV-Kurkino virus circulating in Germany.

The symptoms of HFRS usually appear 2-3 weeks after infection, and the progression of the disease is categorized into several stages: the febrile, hypotensive, oliguric, and diuretic phases, followed by convalescence. The initial symptoms include fever, body pain, and respiratory and gastrointestinal disorders, followed by a reduction in platelet levels, proteinuria, and onset of renal failure. PUUV and DOBV can cause acute interstitial nephritis with kidney injury $[7,10]$. However, the clinical diagnosis of the disease is difficult, and serological tests such as assessment of specific IgG and IgM antibodies against the virus are generally used for diagnosis [1].

Tubular proteinuria occurs in interstitial renal disease and is caused by a reduced reabsorption of low-molecular-weight proteins $\left(\alpha_{1}-\right.$ and $\beta_{2}$-microglobulin) that are normally ultrafiltered at the glomerular level and reabsorbed by the tubular epithelia [11]. The qualitative analysis of proteinuria is usually performed by electrophoresis on cellulose acetate or agarose after protein concentration. However, evaluation of proteinuria in DOBV infection and its predictive value on initial hemodialysis (HD) and prognosis has not been performed so far. In this study, we analyzed the clinical symptoms and proteinuria within the largest series of DOBV-infected patients in Central Europe. We report on the use of urine protein parameters such as levels of albumin, IgG, as well as $\alpha_{1}$ - and $\beta_{2}$-microglobulin as prognostic markers for Dobrava-Belgrade hantavirus infection. 
Meier et al.: Dobrava-Belgrade Hantavirus Infection

Table 1. Patient characteristics at admission $(n=34)$

\begin{tabular}{lr}
\hline Criterion & \\
\hline Patient age, years & $41 \pm 14$ \\
Sex, m/f & $23 / 11$ \\
Body mass index & $28.3 \pm 8.4$ \\
Duration of symptoms prior to hospital & \\
$\quad$ admission, days & $6 \pm 1.4$ \\
Hemodialysis & $4(11.8 \%)$ \\
Kidney biopsy & $6(17.6 \%)$ \\
Symptoms & \\
Fever (>38.0 $\left.{ }^{\circ} \mathrm{C}\right)$ & $28(82.4 \%)$ \\
Chills & $8(23.5 \%)$ \\
Flank pain & $18(52.3 \%)$ \\
Back pain & $4(11.8 \%)$ \\
Diarrhea & $8(23.5 \%)$ \\
Nausea/vomiting & $14(41.2 \%)$ \\
Abdominal pain & $8(23.5 \%)$ \\
Fatigue & $6(17.6 \%)$ \\
Headache & $9(26.5 \%)$ \\
Myalgias/arthralgias & $9(26.5 \%)$ \\
\hline
\end{tabular}

Values are presented as mean \pm standard deviation, $n / n$, or $n(\%)$.

\section{Patients and Methods}

\section{Patients}

A total of 34 patients with acute renal failure of unknown origin were admitted to the University of Lübeck's emergency department between 1997 and 2012. All patients (23 male, 11 female; age range $22-60$ years, mean \pm SD: $41 \pm 14$ years) resided in rural areas and had been healthy prior to the viral infection. All patients denied any previous history of kidney disease, use of prior medication, and pursuance of temporary employment abroad at the assumed time of infection. HD was required in 4 of 34 patients because of hyperkalemia (2 patients) and uremic symptoms with severe acidosis (2 patients); kidney biopsy was performed in 6 patients (biopsies were analyzed in the Pathology Department of the University Clinic of Hamburg, Germany) since serological tests yielded ambiguous results and renal impairment showed no improvement within the first 7 days after hospital admission. On the day of admission, routine laboratory parameters were determined, including measurement of serum creatinine, urea, potassium, as well as blood gas and thrombocyte levels. Spontaneous urine as well as collected urine (collection period of at least $8 \mathrm{~h}$ ) were used for urinalysis.

\section{Urinalysis and Serological Tests}

Quantitative analysis of urinary proteins was performed using a standard immunoluminometric assay $[12,13]$. The urinary concentrations of albumin, IgG, and $\alpha_{1}$-microglobulin were measured with an automatic nephelometer (S100; Dade Behring, Schwalbach, Germany). For detection of $\beta_{2}$-microglobulin, a 10- $\mu \mathrm{L}$ urine sample was diluted in phosphate buffer $\left(0.05 \mathrm{M}\right.$ phosphate, $0.15 \mathrm{M} \mathrm{NaCl}, 0.05 \mathrm{M}$ PBST, $\mathrm{pH} 7.5$ ) and incubated with anti- $\beta_{2}$-microglobulin antibody (1:200; Dade Behring)-coated polystyrene beads for $90 \mathrm{~min}$. Then, the samples were washed and $200 \mu \mathrm{L}$ ABEN-conjugated anti- $\beta_{2}$-microglobulin antibody (1:200) was added. Oxidation of ABEN was initiated with $\mathrm{H}_{2} \mathrm{O}_{2}$ after 60 min of incubation, and emission was detected using a luminometer (CliniLumat LB 953; Berthold, Bundoora, Australia). The concentrations of standard proteins were measured in parallel to derive a reference graph for quantification of test proteins in the urine samples. Reference values were defined as 
Table 2. Laboratory parameters

\begin{tabular}{|c|c|c|c|c|c|}
\hline Parameter & $\begin{array}{l}\text { Reference } \\
\text { values }\end{array}$ & $\begin{array}{l}\text { Baseline } \\
(n=34)\end{array}$ & $\begin{array}{l}3-7 \text { days } \\
(n=34)\end{array}$ & $\begin{array}{l}10-17 \text { days } \\
(n=34)\end{array}$ & $\begin{array}{l}1 \text { year } \\
(n=32)\end{array}$ \\
\hline Creatinine, $\mu \mathrm{M}$ & $\begin{array}{l}61.6-105.6(\mathrm{~m}) \\
44.0-79.2(\mathrm{f})\end{array}$ & $728 \pm 281$ & $282 \pm 186$ & $142 \pm 147^{*}$ & $102 \pm 26^{*}$ \\
\hline $\mathrm{eGFR}, \mathrm{mL} / \mathrm{min} / 1.73 \mathrm{~m}^{2}$ & $>90$ & $7 \pm 14$ & $27 \pm 26$ & $57 \pm 20^{*}$ & $84 \pm 16^{*}$ \\
\hline Leukocytes, cells/nL & $\begin{array}{l}3.9-9.8(\mathrm{~m}) \\
4.0-10.4(\mathrm{f})\end{array}$ & $10.3 \pm 6.4$ & $10.5 \pm 4.6$ & $8.6 \pm 3.2$ & $8.4 \pm 2.3$ \\
\hline Platelets, cells/nL & $\begin{array}{l}146-321(\mathrm{~m}) \\
176-391(\mathrm{f})\end{array}$ & $165 \pm 113$ & $254 \pm 146$ & $326 \pm 176$ & $378 \pm 124$ \\
\hline Hemoglobin, mg/L & $\begin{array}{l}13.5-17.5(\mathrm{~m}) \\
12.6-16.0(\mathrm{f})\end{array}$ & $10.7 \pm 4.5$ & $11.2 \pm 2.5$ & $11.9 \pm 3.2$ & $12.2 \pm 2.8$ \\
\hline C-reactive protein, $\mathrm{mg} / \mathrm{dL}$ & $<5$ & $64 \pm 55$ & $26 \pm 17$ & $17 \pm 8^{*}$ & $4 \pm 6^{*}$ \\
\hline Lactate dehydrogenase, $\mathrm{U} / \mathrm{L}$ & $135-225$ & $287 \pm 45$ & $234 \pm 37$ & $225 \pm 35$ & $206 \pm 42$ \\
\hline
\end{tabular}

Values are presented as range or mean \pm standard deviation. ${ }^{*} p<0.05$ compared to baseline. eGFR, estimated glomerular filtration rate (CKD-EPI formula).

$<25 \mathrm{mg}$ albumin/g creatinine, $<14 \mathrm{mg} \alpha_{1}$-microglobulin/g creatinine, $<2 \mathrm{mg} \beta_{2}$-microglobulin/g creatinine, $<2 \mathrm{mg} \alpha_{2}$-macroglobulin/g creatinine, and $<10 \mathrm{mg}$ IgG/g creatinine. All other laboratory parameters were measured using standard procedures.

Hantavirus infection was determined by IgG and IgM enzyme-linked immunosorbent assays (ELISAs) using hantavirus species-specific nucleocapsid proteins. Positive and uncertain ELISA results were confirmed by a commercial immunoblot assay (recomLine Bunyavirus IgG/IgM; Mikrogen, Neuried, Germany).

Nine DOBV-positive samples were further characterized using the chemiluminescencefocus reduction neutralizing test [7]. Reciprocal neutralizing titers of $\geq 1: 40$ were considered positive. The following virus strains were used for neutralization assays: PUUV, strain Sotkamo [14]; DOBV-Kurkino, strain Slovakia [15]; DOBV-Dobrava, strain Slovenia; and DOBV-Sochi, strain Ap1584 [16].

\section{Statistics}

Continuous variables are expressed as means \pm standard deviations. Qualitative variables are expressed as numbers and percentages in each class. All data were assessed for normality of distribution and equality of variance. For differences between the groups, the paired $t$ test or the Mann-Whitney rank-sum test was used. Qualitative variables were tested using $\chi^{2}$ or Fisher exact test. ANOVA on ranks was used to calculate the difference of tubular proteinuria between patients with or without HD treatments. A $p$ value $<0.05$ was considered to be significant. Statistical analysis was performed using the SigmaPlot 13.0 software (Systat Software GmbH, Erkrath, Germany).

\section{Results}

A total of 34 patients with serologically confirmed DOBV infection were included in the study. The average age of the patients was 41 years, and more male patients (68\%) were admitted to the hospital than female patients (32\%) with symptoms of renal failure. The 
Meier et al.: Dobrava-Belgrade Hantavirus Infection

Table 3. Kidney function and proteinuria at admission

\begin{tabular}{lcc}
\hline Parameter & $\begin{array}{c}\text { Patients with } \\
\text { HD }(n=4)\end{array}$ & $\begin{array}{c}\text { Patients without } \\
\text { HD }(n=30)\end{array}$ \\
\hline Serum creatinine, $\mu \mathrm{M}$ & $808 \pm 181$ & $638 \pm 97$ \\
eGFR, mL/min/1.73 m & $6.2 \pm 2.2$ & $9.4 \pm 3.5$ \\
Thrombocytes, cells/nL & $205 \pm 43$ & $149 \pm 37$ \\
$\alpha_{1}$-MiG, mg/g creatinine & $189 \pm 18$ & $46 \pm 12^{*}$ \\
$\beta_{2}-\mathrm{MiG}, \mathrm{mg} / \mathrm{g}$ creatinine & $36 \pm 9$ & $13 \pm 9^{*}$ \\
Albumin, mg/g creatinine & $1,013 \pm 378$ & $785 \pm 346$ \\
IgG, mg/g creatinine & $242 \pm 94$ & $192 \pm 63$ \\
\hline
\end{tabular}

Values are presented as mean \pm standard deviation. eGFR, estimated glomerular filtration rate (CKD-EPI formula); HD, hemodialysis; MiG, microglobulin. ${ }^{*} p<0.05$ (Mann-Whitney rank-sum test).

Table 4. Urinary protein analysis

\begin{tabular}{llcccc}
\hline Parameter & $\begin{array}{l}\text { Reference } \\
\text { values }\end{array}$ & $\begin{array}{l}\text { Baseline } \\
(n=34)\end{array}$ & $\begin{array}{l}3-7 \text { days } \\
(n=33)\end{array}$ & $\begin{array}{l}10-17 \text { days } \\
(n=31)\end{array}$ & $\begin{array}{l}1 \text { year } \\
(n=32)\end{array}$ \\
\hline Albumin, mg/g creatinine & $<10$ & $711 \pm 579$ & $219 \pm 20$ & $107 \pm 62^{*}$ & $21 \pm 14^{*}$ \\
$\alpha_{1}-\mathrm{MiG}, \mathrm{mg} / \mathrm{g}$ creatinine & $<14$ & $92 \pm 199$ & $62 \pm 129$ & $44 \pm 51^{*}$ & $12 \pm 18^{*}$ \\
$\beta_{2}-\mathrm{MiG}, \mathrm{mg} / \mathrm{g}$ creatinine & $<2$ & $11 \pm 29$ & $4 \pm 3^{*}$ & $4 \pm 3^{*}$ & $4 \pm 2^{*}$ \\
$\alpha_{2}-\mathrm{MaG}, \mathrm{mg} / \mathrm{g}$ creatinine & $<2$ & $11 \pm 20$ & $4 \pm 8^{*}$ & $0 \pm 1^{*}$ & $0 \pm 0^{*}$ \\
IgG, mg/g creatinine & $<10$ & $144 \pm 83$ & $65 \pm 8$ & $25 \pm 16^{*}$ & $10 \pm 4^{*}$ \\
\hline
\end{tabular}

Values are presented as mean \pm standard deviation. MaG, macroglobulin; MiG, microglobulin. ${ }^{*} p<0.05$ compared to baseline.

patients had been healthy prior to the infection, with a mean body mass index of 28.3, and had exhibited various symptoms for at least 6 days before being admitted to the hospital. The most prevalent symptoms were high-grade fever (82.4\%) accompanied by flank pain $(52.3 \%)$ and nausea (41.2\%) (Table 1).

On average, serum creatinine levels were elevated $(728 \mu \mathrm{m})$ and the estimated glomerular filtration rate was low $\left(7 \mathrm{~mL} / \mathrm{min} / 1.73 \mathrm{~m}^{2}\right.$ ) at baseline (time of admission) (Table 2), indicating kidney failure. The serum creatinine concentrations in the dialyzed patients were higher than those in the undialyzed patients, but the difference did not reach statistical significance ( $p=0.068$, Mann-Whitney rank-sum test) (Table 3 ). In addition, the C-reactive protein and leukocyte levels were high in all patients, which was indicative of infection. In contrast, the mean platelet count $(165 / \mathrm{nL}$ ) was significantly lower at baseline (Table 2), which represented a characteristic sign of HFRS. These parameters improved gradually with time and returned to nearly normal levels within 1 year of follow-up (Table 2).

Urinalysis revealed elevated levels of albumin $\left(711 \pm 579 \mathrm{mg} / \mathrm{g}\right.$ creatinine), $\beta_{2^{-}}$ microglobulin ( $11 \pm 29 \mathrm{mg} / \mathrm{g}$ creatinine), $\alpha_{1}$-microglobulin $(92 \pm 199 \mathrm{mg} / \mathrm{mg}$ creatinine), and IgG (144 $\pm 83 \mathrm{mg} / \mathrm{g}$ creatinine) (Table 4). The urinary levels of $\alpha_{2}$-macroglobulin were also elevated at baseline, suggesting postglomerular proteinuria, since $\alpha_{2}$-macroglobulin does not pass the glomerular basement membrane (Table 3) [17]. However, all the above parameters gradually returned to physiological levels in the course of the 1-year follow-up, which coincided with improvement in the patients' symptoms and health (Table 4).

Four patients underwent HD and 6 patients underwent kidney biopsy (Tables 1,3). Only 2 of the 4 patients with renal replacement therapy were biopsied. Kidney biopsies were 

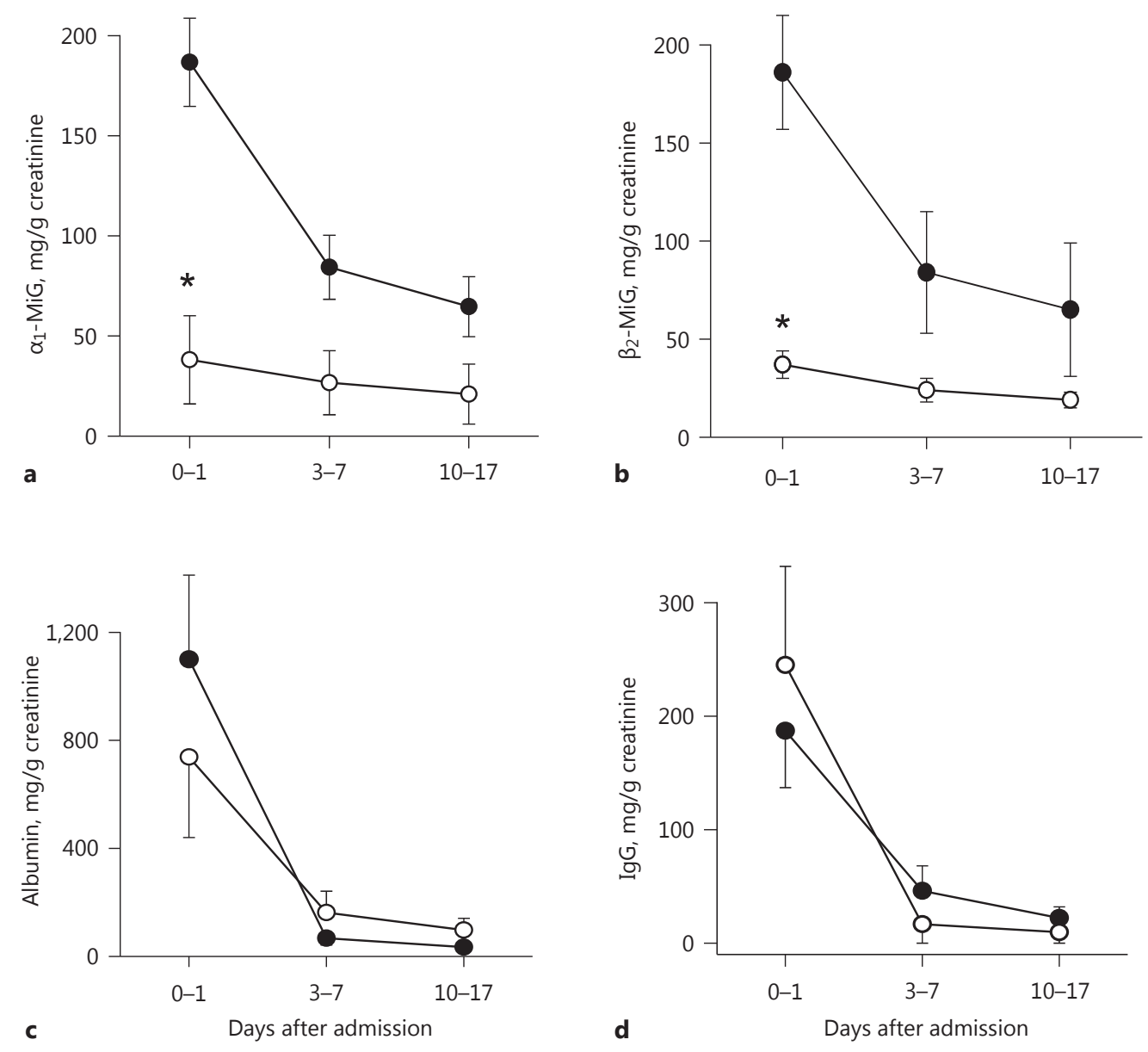

Fig. 1. Proteinuria in Dobrava-Belgrade virus (DOBV)-infected patients. $\alpha_{1}$-Microglobulin $\left(\alpha_{1}\right.$-MiG) (a), $\beta_{2}$-microglobulin $\left(\beta_{2}-\mathrm{MiG}\right)$ (b), albumin (c), and IgG (d) were determined in urinary samples of DOBV-infected patients with (black symbols) or without (white symbols) hemodialysis treatment at hospital admission and during follow-up. ${ }^{*} p<0.05$.

performed according to the expertise of the senior nephrologist on duty during hospital admission of the particular patient.

All kidney biopsies showed diffuse interstitial infiltrates of mononuclear cells in the renal cortex ( $>25 \%$ of the parenchyma affected) with active invasion of tubules consistent with severe signs of acute tubule inflammation. Trichrome staining showed cellular interstitial infiltrates in the outer medulla, but also renal vascular endothelial injury with erythrocyte extravasates in the cortex-medullary border. The latter histopathological finding is strongly consistent with acute hantavirus infection [18]. Electron microscopy did not show any severe glomerular damage.

Comparison of the urinary $\alpha_{1}$ - and $\beta_{2}$-microglobulin levels between patients who did or did not undergo HD revealed that these ratios were higher in the patients who needed HD (Table 3), highlighting the severity of their symptoms among the cases studied. Interestingly, these ratios decreased with time in both groups (HD versus non-HD) (Fig. 1a, b). Nonetheless, correlation analysisshowed a significant association between urinary $\alpha_{1}$-and $\beta_{2}$-microglobulin levels and the severity of kidney injury, reflected by the serum creatinine concentration at 


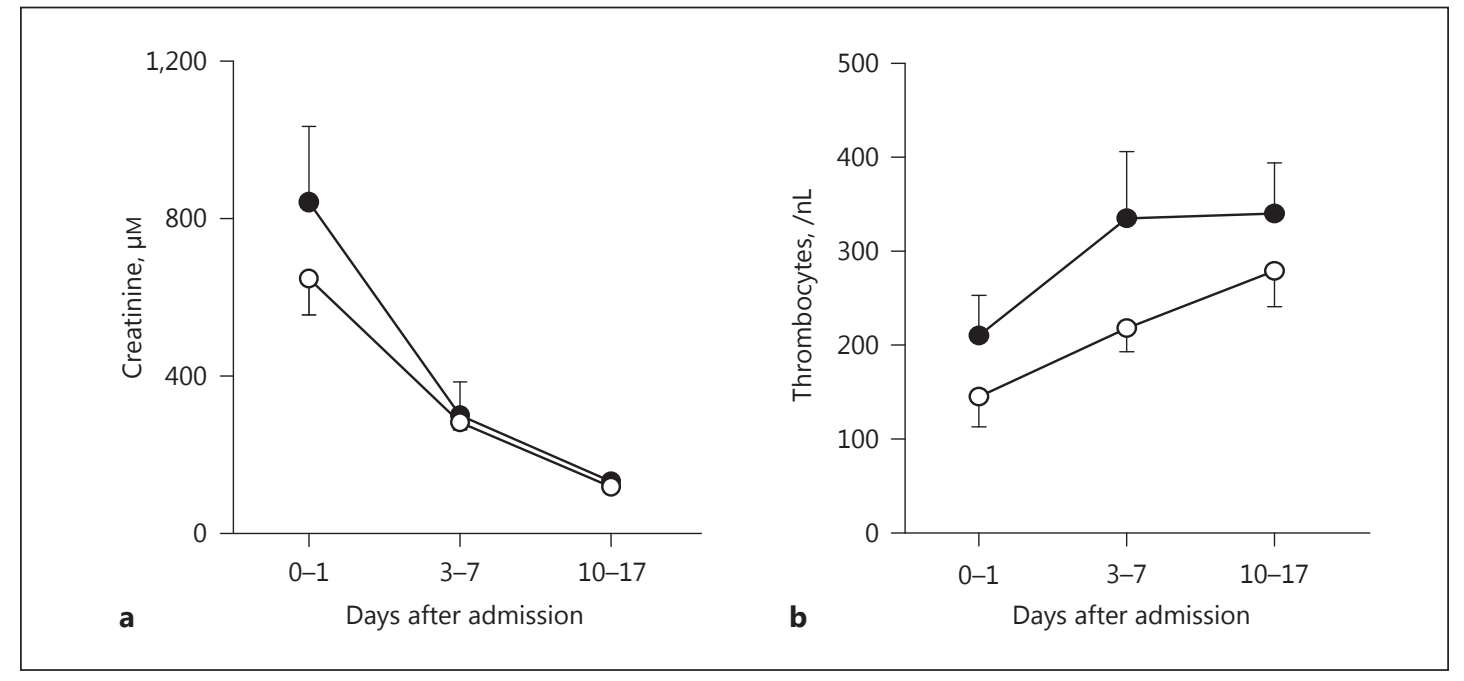

Fig. 2. Laboratory parameters of Dobrava-Belgrade virus (DOBV)-infected patients. Creatinine (a) and thrombocytes (b) were determined in patients with DOBV-associated acute kidney injury with (black symbols) or without (white symbols) hemodialysis treatment at hospital admission (baseline), after 3-7 days, and after 10-17 days.

hospital admission $\left(\mathrm{t}_{0}\right)(p<0.001, r=0.89$ Spearman rank-order correlation). Interestingly, no correlation between creatinine values and tubular proteinuria was observed at hospital discharge $\left(\mathrm{t}_{10-17}\right)$.

In contrast, the ratios of urinary albumin and urinary IgG drastically decreased with time (3-7 days) in both groups to almost similar levels ( $p \leq 0.05$; Fig. 1c, d). The creatinine levels also decreased in both groups by 10-17 days (Fig. 2a). However, renal function and glomerular proteinuria did not show significant correlation $(p=0.09, r=0.74$ Spearman rank-order correlation).

On the contrary, the thrombocyte (platelet) numbers increased and plateaued in the HD group, whereas they showed an increasing trend in the non-HD group after 10-17 days of follow-up (Fig. 2b). Altogether, the data showed that the viral infection waned with time, resulting in improvement of renal function and pathological parameters.

\section{Discussion}

Hantavirus disease after DOBV infection is a viral hemorrhagic fever that is characterized by acute kidney injury (AKI) and thrombocytopenia. The disease is caused by interstitial nephritis associated with tubular proteinuria, which is explained by decreased tubular reabsorption of low-molecular-weight proteins after ultrafiltration in the glomerulus $[19,20]$.

In our study, the urinary ratios of albumin/creatinine and IgG/creatinine were elevated in DOBV-infected patients, suggesting glomerular injury, which is not a typical finding in interstitial nephritis $[19,20]$. This finding might be explained by an elevated $\alpha_{2}$-macroglobulin level in the urine of our patients, indicating postglomerular proteinuria, since $\alpha_{2}$-macroglobulin does not pass the glomerular basement membrane [18]. Another possibility might be the effacement of a podocyte foot process leading to transient glomerular proteinuria, which has been described in the case of a patient with PUUV-associated hantavirus disease, also called NE [21]. Supporting evidence that glomerular injury in our patients was not present was 
obtained from the results of the kidney biopsies, since glomerular damage was not verified in any of our histological kidney samples. However, the levels of $\alpha_{1}$ - and $\beta_{2}$-microglobulin were five-fold elevated above the reference values in all of our DOBV-infected patients with AKI demonstrating severe tubular damage.

Tubular proteinuria has not been used to assess the progression of DOBV infections so far. In our study, we determined the level of tubular proteinuria in the urine samples of 34 patients with DOBV infection-induced renal failure at their time of admission to hospital and over a follow-up period of 1 year. These values were correlated with the status of the renal injury over time to determine whether they can be used as prognostic markers for DOBV infection. We found that the extent of tubular proteinuria in DOBV infection-induced AKI at admission showed a positive correlation with renal function and the need for renal replacement therapy. On the other hand, tubular and glomerular proteinuria showed no positive correlation with renal function or clinical outcome at hospital discharge, indicating the self-limiting character of the disease. Interestingly, the urinary proteins of our patients were still elevated at 1-year follow-up, which has also been reported in PUUV infections after a follow-up period of 7-35 months [22]. It is not clear whether this persistent proteinuria in DOBV-infected patients indicates chronic kidney injury. However, persistent proteinuria was not associated with chronic kidney injury or other long-term consequences in patients with NE [22].

Glomerular proteinuria is used as a predictive marker for Puumala hantavirus-induced interstitial nephritis [23]; a dipstick albumin assessment was performed on 205 patients with acute PUUV infection upon hospitalization, and the amounts of albumin, IgG, creatinine, and $\alpha_{1}$-microglobulin were determined for 3 consecutive days. In acute PUUV infection, maximum median proteinuria values preceded the most severe phase of AKI by a few days [23]. Therefore, simple dipstick albumin testing was able to predict upcoming AKI. Similarly, proteinuria (a dipstick protein value of $>1.5 \mathrm{~g} / \mathrm{L}$ [RR 1.59, 95\% CI 1.09-2.33; $p=0.016]$ ) was shown to be associated with oliguric or anuric HFRS induced by PUUV or DOBV in an analysis of 128 patients in Zagreb, Croatia [24]. Remarkably, only 21\% of these hantavirus-infected patients were tested positive against DOBV, and multivariate analysis did not differentiate between DOBV- and PUUV-infected patients [24]. This might explain why glomerular proteinuria was not able to predict the clinical course of our patients with DOBV-associated AKI. Moreover, DOBV-Kurkino hantavirus infections in Northern Germany have been reported to cause milder disease compared to DOBV infections on the Balkans and in Southern Europe [6-8], suggesting different predictive urinary protein markers for AKI. Since only 4 of our DOBV-infected patients needed renal replacement therapy, the conflicting results compared to other larger studies might also be explained with our small sample size.

A cross-sectional prospective study of 456 PUUV-infected patients in Germany revealed that $88 \%$ had AKI. After a follow-up of 7-35 months, all patients had detectable hantavirusspecific IgG, $25 \%$ had hematuria, whereas only $7 \%$ showed proteinuria. Therefore, proteinuria was not considered to have long-term clinical consequences, unlike hematuria [24]. However, peak creatinine levels were higher and proteinuria was present in the patients with severe thrombocytopenia, a characteristic of NE [24-26]. These results are in line with our observation that the amount of glomerular and tubular proteinuria does not influence the longterm outcome and renal function of patients with DOBV-associated AKI.

Few parameters other than the amount of protein excreted in the urine are used to assess and predict the severity of NE. For example, Bunz et al. [27] showed that the peak creatinine concentrations in PUUV-infected individuals with AKI showed significant correlation with high plasma levels of urinary neutrophil gelatinase-associated lipocalin (uNGAL), urine albumin/creatinine ratio, urine protein/creatinine ratio, and urine dipstick protein levels. Among these, uNGAL accurately predicts the severity of AKI in NE. A prospective study using a cohort of 118 Scandinavian patients hospitalized with NE showed that, unlike high C-reactive 
protein levels, high interleukin-6 levels correlated with the severity of NE along with the presence of other predictive factors such as high leukocyte count, low platelet count, urinary protein excretion, and urinary output. Thus, interleukin-6 levels could be used as a predictive marker for PUUV-associated NE [28]. The same group showed that the levels of urokinasetype plasminogen activator receptor (UPAR) were upregulated during PUUV infectioninduced renal inflammation and that the levels of fractionally excreted soluble uPAR correlated with the acuteness of the infection and proteinuria and decreased with convalescence. This was an important finding, as UPAR is known to upregulate $\beta 3$ integrins, receptors that are utilized by the virus for entering endothelial cells. Therefore, uPAR levels are a direct readout for the severity of the infection and its subsequent effects, such as reduced platelet count, proteinuria, or urinary output [29].

In a study by Rasche et al. [30], a low platelet count $\left(<60 \times 10^{9} / \mathrm{L}\right)$ appeared as a predictive marker of a severe clinical course of acute renal failure in 15 patients with NE. In contrast, our results showed similar platelet concentrations in DOBV-infected patients with or without HD therapy, indicating that platelets are not predictive in DOBV-associated kidney injury.

In our study, we identified several factors that could be used to assess the severity and progression of DOBV infection. Although the initial symptoms of DOBV-Kurkino and PUUV infections in Germany are similar, the manifestation of DOBV has not been reported in larger patient population so far, and therefore the determination of its prognostic features was essential. Similar to those of PUUV infection-induced AKI, the stage and severity of DOBV infection-associated renal damage could be predicted by the levels of several proteins $\left(\alpha_{1^{-}}\right.$ and $\beta_{2}$-microglobulin) found in the urine of renal reabsorption-impaired patients. Interestingly, the levels of $\alpha_{1}$ - and $\beta_{2}$-microglobulin were higher in the patients who required HD than in those who did not require HD, indicating that these parameters correctly predicted the severity of the disease and could hence be used for diagnosis and deciding the mode of treatment. However, estimation of proteinuria might also be coupled with the determination of other related markers such as UPAR and UNGAL for a more accurate prognosis.

\section{Statement of Ethics}

The study was approved by the ethics committee of the University of Lübeck.

\section{Disclosure Statement}

The authors declare that they have no conflict of interest and received no funding. The results presented in this paper have not been published previously in whole or part, except in abstract form.

\section{References}

1 Krüger DH, Ulrich RG, Hofmann J: Hantaviruses as zoonotic pathogens in Germany. Dtsch Arztebl Int 2013; 110:461-467.

-2 Kruger DH, Figueiredo LT, Song JW, Klempa B: Hantaviruses - globally emerging pathogens. J Clin Virol 2015; 64:128-136.

3 Schmaljohn C, Hjelle B: Hantavirus: a global disease problem. Emerg Infect Dis 1997;3:95-104.

-4 Vaheri A, Henttonen H, Voutilainen L, Mustonen J, Sironen T, Vapalahti O: Hantavirus infections in Europe and their impact on public health. Rev Med Virol 2013;23:35-49.

5 Klempa B, Avsic-Zupanc T, Clement J, Dzagurova TK, Henttonen H, Heyman P, Jakab F, Kruger DH, Maes P, Papa A, Tkachenko EA, Ulrich RG, Vapalahti O, Vaheri A: Complex evolution and epidemiology of Dobrava-Belgrade hantavirus: definition of genotypes and their characteristics. Arch Virol 2013;158:521-529. 
6 Dzagurova TK, Klempa B, Tkachenko EA, Slyusareva GP, Morozov VG, Auste B, Kruger DH: Molecular diagnostics of hemorrhagic fever with renal syndrome during a Dobrava virus infection outbreak in the European part of Russia. J Clin Microbiol 2009;47:4029-4036.

-7 Hofmann J, Meier M, Enders M, Führer A, Ettinger J, Klempa B, Schmidt S, Ulrich RG, Kruger DH: Hantavirus disease in Germany due to infection with Dobrava-Belgrade virus genotype Kurkino. Clin Microbiol Infect 2014;20:0648-0655.

8 Schütt M, Gerke P, Meisel H, Ulrich R, Krüger DH: Clinical characterization of Dobrava hantavirus infections in Germany. Clin Nephrol 2001;55:371-374.

-9 Schütt M, Meisel H, Krüger DH, Ulrich R, Dalhoff K, Dodt C: Life-threatening Dobrava hantavirus infection with unusually extended pulmonary involvement. Clin Nephrol 2004;62:54-57.

10 Mustonen J, Outinen T, Laine O, Pörsti I, Vaheri A, Mäkelä S: Kidney disease in Puumala hantavirus infection. Infect Dis (Lond) 2017;49:321-332.

11 Miettinen MH, Makela SM, Ala-Houhala IO, Huhtala HS, Koobi T, Vaheri AI, Pasternack AI, Porsti IH, Mustonen JT: Tubular proteinuria and glomerular filtration 6 years after Puumala hantavirus-induced acute interstitial nephritis. Nephron Clin Pract 2009;112:c115-c120.

12 Steinhoff J, Bühner U, Feddersen A, Wood WG, Wiedemann G, Preuss R, Fricke L, Färber P, Hoyer J, Sack K: Analysis of C-reactive protein in urine as an aid in the clinical diagnosis of disturbed renal transplant function. Transplant Proc 1992;24:2735-2737.

13 Wood WG, Steinhoff J, Fricke L: Relative molecular mass influences the results obtained when determining urinary proteins by laser nephelometry. J Immunol Methods 1990;131:151-152.

14 Vapalahti O, Kallio-Kokko H, Salonen EM, Brummer-Korvenkontio M, Vaheri A: Cloning and sequencing of Puumala virus Sotkamo strain S and M RNA segments: evidence for strain variation in hantaviruses and expression of the nucleocapsid protein. J Gen Virol 1992;73:829-838.

15 Klempa B, Stanko M, Labuda M, Ulrich R, Meisel H, Kruger DH: Central European Dobrava hantavirus isolate from a striped field mouse (Apodemus agrarius). J Clin Microbiol 2005;43:2756-2763.

-16 Klempa B, Tkachenko EA, Dzagurova TK, Yunicheva YV, Morozov VG, Okulova NM, Slyusareva GP, Smirnov A, Kruger DH: Hemorrhagic fever with renal syndrome caused by 2 lineages of Dobrava hantavirus, Russia. Emerg Infect Dis 2008;14:617-625.

17 Delanghe J: New screening diagnostic techniques in urinalysis. Acta Clin Belg 2007;62:155-161.

-18 Gnemmi V, Verine J, Vrigneaud L, Glowacki F, Ratsimbazafy A, Copin MC, Dewilde A, Buob D: Microvascular inflammation and acute tubular necrosis are major histologic features of hantavirus nephropathy. Hum Pathol 2015;46:827-835.

19 Clarkson MR, Giblin L, O’Connell FP, O’Kelly P, Walshe JJ, Conlon P, O’Meara Y, Dormon A, Campbell E, Donohoe $\mathrm{J}$ : Acute interstitial nephritis: clinical features and response to corticosteroid therapy. Nephrol Dial Transplant 2004;19:2778-2783.

20 Neilson EG: Pathogenesis and therapy of interstitial nephritis. Kidney Int 1989;35:1257-1270.

21 Boehlke C, Hartleben B, Huber TB, Hopfer H, Walz G, Neumann-Haefelin E: Hantavirus infection with severe proteinuria and podocyte foot-process effacement. Am J Kidney Dis 2014;64:452-456.

22 Latus J, Schwab M, Tacconelli E, Pieper FM, Wegener D, Rettenmaier B, Schwab A, Hoffmann L, Dippon J, Müller S, Fritz P, Zakim D, Segerer S, Kitterer D, Kimmel M, Gußmann K, Priwitzer M, Mezger B, Walter-Frank B, Corea A, Wiedenmann A, Brockmann S, Pöhlmann C, Alscher MD, Braun N: Acute kidney injury and tools for risk-stratification in 456 patients with hantavirus-induced nephropathia epidemica. Nephrol Dial Transplant 2015;30:245-251.

-23 Mantula PS, Outinen TK, Clement JP, Huhtala HS, Pörsti IH, Vaheri A, Mustonen JT, Mäkelä SM: Glomerular proteinuria predicts the severity of acute kidney injury in Puumala hantavirus-induced tubulointerstitial nephritis. Nephron 2017;136:193-201.

-24 Turčinov D, Puljiz I, Markotić A, Kuzman I, Begovac J: Clinical and laboratory findings in patients with oliguric and non-oliguric hantavirus haemorrhagic fever with renal syndrome: an analysis of 128 patients. Clin Microbiol Infect 2013;19:674-679.

25 Latus J, Kitterer D, Segerer S, Artunc F, Alscher MD, Braun N: Severe thrombocytopenia in hantavirus-induced nephropathia epidemica. Infection 2015;43:83-87.

-26 Latus J, Schwab M, Tacconelli E, Pieper FM, Wegener D, Dippon J, Müller S, Zakim D, Segerer S, Kitterer D, Priwitzer M, Mezger B, Walter-Frank B, Corea A, Wiedenmann A, Brockmann S, Pöhlmann C, Alscher MD, Braun N: Clinical course and long-term outcome of hantavirus-associated nephropathia epidemica, Germany. Emerg Infect Dis 2015;21:76-83.

27 Bunz H, Weyrich P, Peter A, Baumann D, Tschritter O, Guthoff M, Beck R, Jahn G, Artunc F, Häring HU, Heyne N, Wagner R: Urinary neutrophil gelatinase-associated lipocalin (NGAL) and proteinuria predict severity of acute kidney injury in Puumala virus infection. BMC Infect Dis 2015;15:464.

-28 Outinen TK, Mäkelä SM, Ala-Houhala IO, Huhtala HS, Hurme M, Paakkala AS, Pörsti IH, Syrjänen JT, Mustonen JT: The severity of Puumala hantavirus induced nephropathia epidemica can be better evaluated using plasma interleukin-6 than C-reactive protein determinations. BMC Infect Dis 2010;10:132.

29 Outinen TK, Mäkelä S, Huttunen R, Mäenpää N, Libraty D, Vaheri A, Mustonen J, Aittoniemi J: Urine soluble urokinase-type plasminogen activator receptor levels correlate with proteinuria in Puumala hantavirus infection. J Intern Med 2014;276:387-395.

30 Rasche FM, Uhel B, Krüger DH, Karges W, Czock D, Hampl W, Keller F, Meisel H, von Müller L: Thrombocytopenia and acute renal failure in Puumala hantavirus infection. Emerg Infect Dis 2004;10:1420-1425. 